\title{
Influence of Small Amounts of Boron on the Structural Evolution of Nanocrystalline Ni3Al During Thermal Treatments
}

\author{
A. Korznikov*,**, O. Dimitrov*, A. Quivy*, G. Korznikova**, J. Devaud* and R. Valiev** \\ * Centre d'Etudes de Chimie Métallurgique, CNRS, 94407 Vitry-sur-Seine, France \\ ** Institute for Metals Superplasticity Problems, Oufa, Russia
}

\begin{abstract}
The influence of a boron addition $(0.1 \mathrm{wt} \%)$ on the structural stability of high-purity nanocrystalline Ni3Al intermetallic compounds was investigated. The nanocrystalline structure was obtained by severe shear deformation under quasi-hydrostatic pressure. Residual electrical resistivity, Vickers microhardness, $\mathrm{X}$-Ray diffraction and transmission electron microscopy were used to characterize the material evolution during thermal treatments in the temperature range $293-1313 \mathrm{~K}$. After severe deformation the materials were disordered with a smaller crystallite size in the boron-doped compound than in the pure one. The boron addition was found to shift the long-range ordering, as well as the recovery of the properties investigated to higher temperatures, i.e. to improve the thermal stability of the structure
\end{abstract}

\section{INTRODUCTION}

The intermetallic compound $\mathrm{Ni3} \mathrm{Al}$ has attractive high-temperature properties, particularly when doped with small amounts of boron which suppress its grain-boundary brittleness [1]. Since the mechanical properties are enhanced by plastic deformation, it is important to understand the structural evolution during subsequent heat treatments.

In undoped $\mathrm{Ni} 3 \mathrm{Al}$ such investigations have up to now been limited by the necessity of using single crystals for performing substantial deformation [1]. In a comparative study of recrystallization in undoped and boron-doped $\mathrm{Ni} 3 \mathrm{Al}$ after a small deformation (compression to $17 \%$ reduction in thickness), Zhou et al [3] found a weak retarding effect of the boron addition.

The aim of the present work was to perform an investigation of the structure evolution of both undoped and boron-doped $\mathrm{Ni3} \mathrm{Al}$ in highly deformed materials. This was made possible by using the process of severe plastic deformation by torsion under hydrostatic pressure [4]; it allows considerable cold-working of pure $\mathrm{NizAl}$ in spite of its grain boundary brittleness. Furthermore, residual electrical resistivity measurements were performed in order to gain new insight with respect to the previous investigation of highly deformed undoped Ni3Al [5].

\section{EXPERIMENTAL PROCEDURE}

The intermetallic alloys chosen for this investigation were a pure binary Ni3Al material $(74.9$ at $\% \mathrm{Ni}, 25.1$ at\% $\mathrm{Al}$ ) and a boron doped material (76.3 at $\% \mathrm{Ni}, 23.7$ at $\% \mathrm{Al}$, referred to $\mathrm{Al}+\mathrm{Ni},+0.1 \mathrm{wt} \% \mathrm{~B})$. They were prepared by melting together weighed quantities of high purity $\mathrm{Ni}, \mathrm{Al}$ and $\mathrm{Ni3}$ B in an inductive plasma furnace. The alloys were homogenized by annealing for 40 hours at $1323 \mathrm{~K}$ in a vacuum of $10^{-6}$ $\mathrm{Pa}$. According to previous investigations [6] the added boron should be in solid solution.

Specimens for deformation, $6 \mathrm{~mm}$ in diameter and $0.3 \mathrm{~mm}$ thick, were prepared by diamond sawing and mechanical polishing. The samples were subjected to shear deformation by torsion at room temperature at a quasi-hydrostatic pressure of $8 \mathrm{GPa}$ in a Bridgman anvil-type unit as described in [4]. The deformation of the samples under study was characterized by a value of the maximum logarithmic shear strain of 6 . Specimens for the investigation of structure and properties were obtained by mechanical polishing to a thickness of $0.2 \mathrm{~mm}$ (for X-ray and microhardness), then spark cutting of disks $3 \mathrm{~mm}$ in diameter (for TEM) or diamond sawing to a rectangular shape of $6 \times 1 \times 0.2 \mathrm{~mm}^{3}$ (for electrical resistivity). 
The electrical resistivity samples were subsequently annealed for $40 \mathrm{~min}$ in the temperature range from $353 \mathrm{~K}$ up to $1313 \mathrm{~K}$ in steps of $60 \mathrm{~K}$ at a reduced He pressure up to $820 \mathrm{~K}$, and in a vacuum of $10^{-4} \mathrm{~Pa}$ at higher temperatures. The other samples were annealed for $40 \mathrm{~min}$ at selected temperatures.

Electron microscopy (TEM) studies of the foils were conducted in a JEM - 2000 FX transmission electron microscope. The foils were prepared by jet polishing.

For estimating the long range order parameter (S) X-ray diffraction was used. The $\mathrm{S}$ values were obtained from the ratio between the intensities of the $\{110\}$ superlattice line and the $\{220\}$ fundamental line [7]. This ratio was corrected by using the intensities of the standard fully ordered $\mathrm{NizAl}$ given in the ASTM file.

Microhardness was measured using a Vickers diamond pyramidal indenter with a load of $0.2 \mathrm{~kg}$.

Electrical resistivities were determined at $4.2 \mathrm{~K}$ by measuring the electrical resistance of the samples and using a geometrically-determined shape factor. The uncertainty on resistivity variations was $5 \times 10^{-9} \Omega \mathrm{cm}$.

\section{EXPERIMENTAL RESULTS}

In the as-deformed state, the structure of both compounds under study consisted of sub-microsized crystallites with large internal stresses as shown by electron microscopic observations. A complex diffraction contrast of the structure could be seen. The main specific features of this structure are that the grain boundaries are not well defined, they are wide and curved. Inside the crystallites an alternating contrast, consisting of dark and bright bands can sometimes be observed. A typical example of this stucture is shown in fig. $1(\mathrm{a}, \mathrm{b}, \mathrm{c})$, where bright field, dark field images and selected area diffraction pattern (from an area of $0.02 \mu \mathrm{m}^{2}$ ) of a Ni3 $\mathrm{Al}+\mathrm{B}$ as-deformed sample are given. The mean grain size of the crystallites, estimated on dark field images was about $50 \mathrm{~nm}$ in the pure material and $35 \mathrm{~nm}$ in the boron-doped one. The diffraction pattern with a large number of spots arranged in circles, provides evidence for the existense of large misorientations between the crystallites.

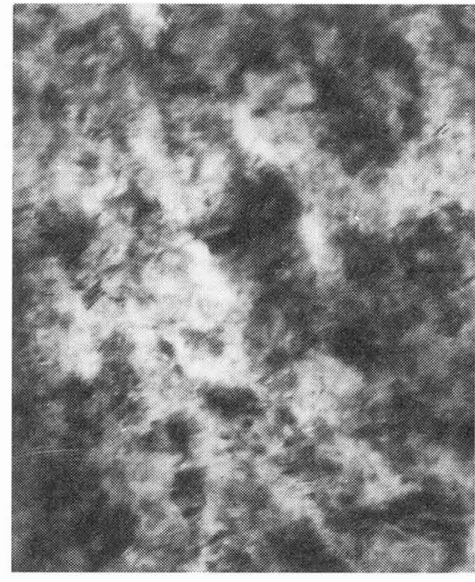

a)

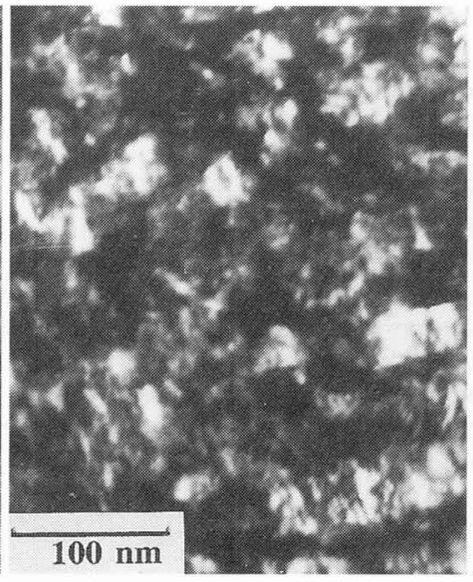

b)

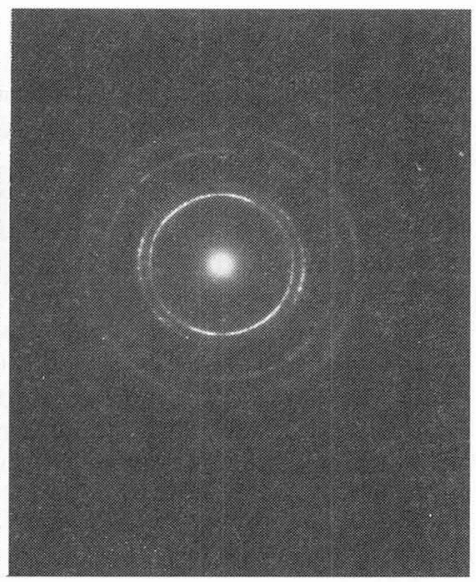

c)

Fig.1 TEM bright field (a), dark field (b) micrograpls, and diffraction pattern (c) of the as-deformed $\mathrm{Ni} 3 \mathrm{Al}+\mathrm{B}$

This structural state is characterized by a high value of residual resistivity (fig. $2 a$ ), comparable to those measured previously in cold-rolled $\mathrm{B}$-doped $\mathrm{Ni}_{3} \mathrm{Al}$ alloys [8]. According to the $\mathrm{X}$-ray diffraction results, both compounds were entirely disordered (fig $3 \mathrm{~b}$ ). The value of microhardness was high and similar for both compounds (fig. $3 a$ ).

The evolution of the residual electrical resistivity on annealing revealed the existence of three main stages of structural change.

- Stage A. In the range $293 \mathrm{~K}-533 \mathrm{~K}$ (for pure $\mathrm{Ni3Al}$ ) resistivity increased, then went through a maximum (fig.2a) and the hardness reached its maximum value of $8820 \mathrm{MPa}$ at $533 \mathrm{~K}$ (fig.3a). In the B-doped 
compound an increase of resistivity and of microhardness was also observed, but the maximum values were reached at $593 \mathrm{~K}$. TEM investigations revealed some increase of the crystallite size, in the pure material only. Long-range ordering became noticeable in the pure material at $533 \mathrm{~K}(\mathrm{~S}=0.27)$ and in the boron doped material at $593 \mathrm{~K}(\mathrm{~S}=0.45)$ (fig.3.b).

- Stage B. In the range $533 \mathrm{~K}-833 \mathrm{~K}$, a strong decrease of resistivity, a weak recovery of hardness and partial long-range ordering took place. According to the resistivity derivative curves, the main decrease of resistivity took place around $560 \mathrm{~K}$ in the pure material and around $680 \mathrm{~K}$ in the boron-doped (fig.2.b). The long range-order parameter in both compounds reached a constant value of about 0.6 at $653 \mathrm{~K}$ and remained the same up to high temperatures (fig.3b). TEM investigations showed that, in both materials, a structural recovery occurs in the beginning of this stage. The crystallites become clearer, alternating contrast inside the crystallites disappears completely but the boundaries are still wide and curved. The mean size of the crystallites scarcely changes in the first part of this stage. Some crystallites with a very perfect interior appear, which might later become recrystallization nuclei. Towards the end of this stage the crystallite size increases significantly and reaches a diameter of about $300 \mathrm{~nm}$ for both materials at $833 \mathrm{~K}$.

- Stage C. Above $833 \mathrm{~K}$ resistivity increased slightly. The microhardness in both alloys continued to decrease down to $2000 \mathrm{MPa}$ at $1313 \mathrm{~K}$, the microhardness in B-doped material being higher than in the pure. The level of long-range-order increased abruptly at $1313 \mathrm{~K}$ and reached 0.77 for the pure and 1.0 for the B-doped material (fig.3b). TEM investigations showed an increase of the mean grain size in both materials. At $1013 \mathrm{~K}$ in the B-doped Ni3Al the mean grain size was $2.6 \mu \mathrm{m}$. Inside the grains some stacking faults, twins and antiphase boundaries may be observed. In pure NizAl the grains are larger, they seem to be clearer, without stacking faults.

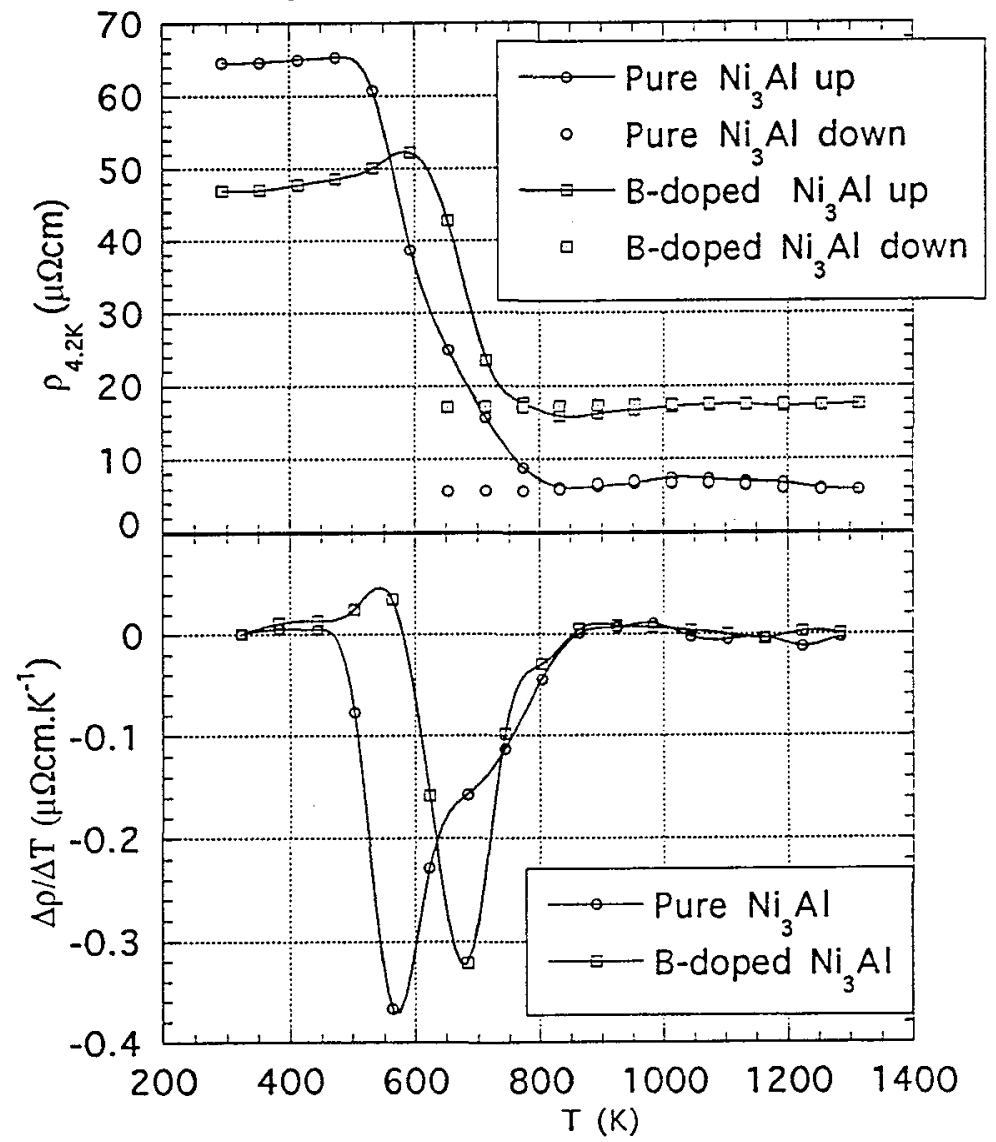

Fig.2 Resistivity variation of $\mathrm{Ni}_{3} \mathrm{Al}$ and $\mathrm{Ni}_{3} \mathrm{Al}+\mathrm{B}$ as a function of the annealing tempcrature. Direct (a) and derivative (b) curves. 


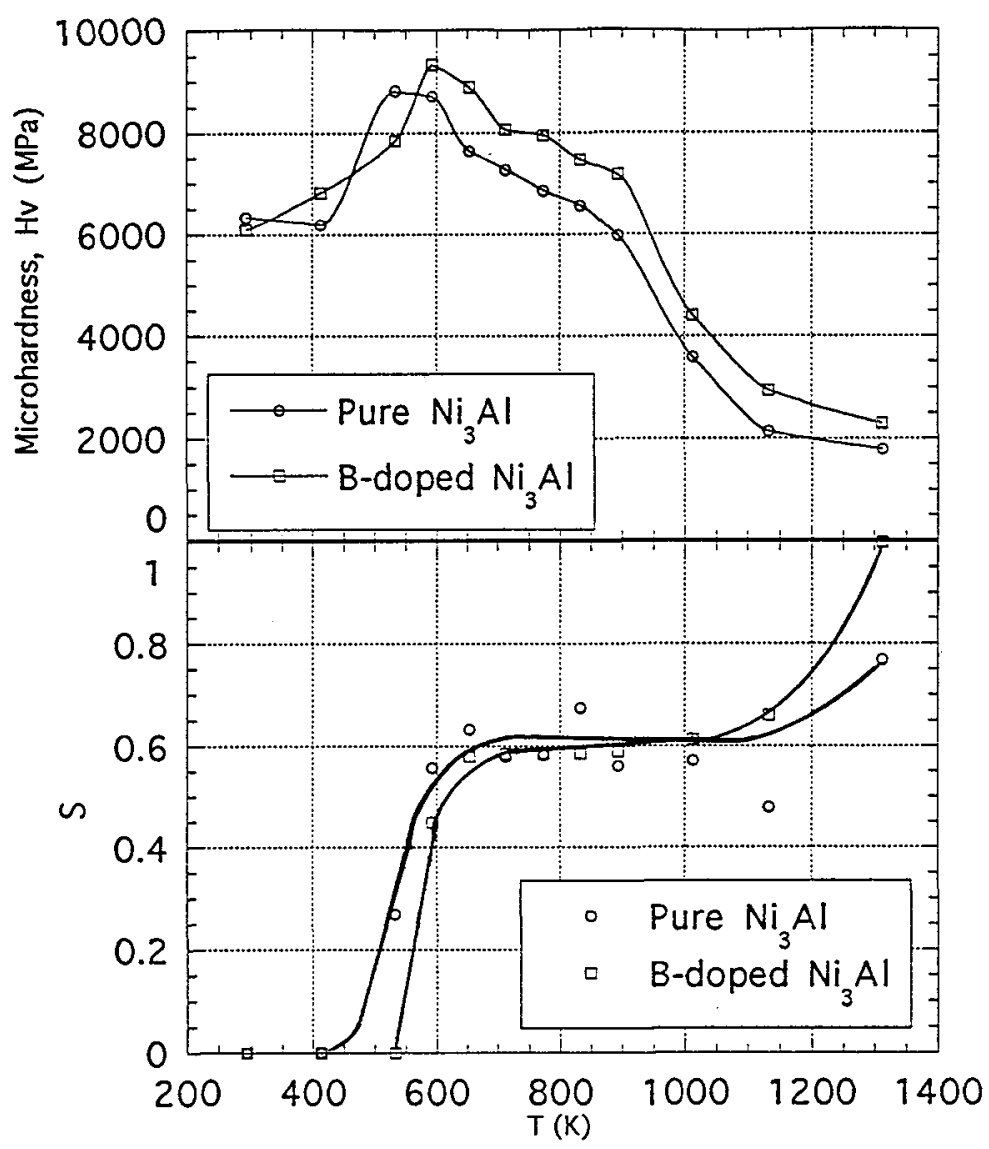

Fig.3 Evolution of hardness $\mathrm{Hv}$ for $\mathrm{Ni}_{3} \mathrm{Al}$ and $\mathrm{Ni}{ }_{3} \mathrm{Al}+\mathrm{B}$ (a), and of the long-range order parameter $\mathrm{S}$ (b) as a function of the annealing temperature.

\section{DISCUSSION}

One of the striking results of the present investigation is the very rapid (but partial) long-range ordering which takes place in stage $\mathrm{A}$ around $530 \mathrm{~K}$ in the pure material and around $590 \mathrm{~K}$ in the boron-doped. This ordering cannot be related to atomic movements promoted by the migration of equilibrium vacancies, since in undeformed samples order variations begin to take place only around $800 \mathrm{~K}$ [9]. It must therefore be connected with the presence of deformation-induced defects, for instance small defect clusters or dislocation loops and arrays which would become unstable and break up with increasing temperature; the corresponding release of vacancies would provide the atomic mobility required for ordering. It should be noted that dislocation arrays may exist at crystallite boundaries and triple junctions in nanocrystalline materials, resulting in high internal stresses [10]. The role of the boron addition could be to stabilize such clusters, loops or arrays, thus delaying their break-up or annihilation up to higher temperatures.

In the same temperature range as long-range ordering, a steep increase in hardness is observed in both alloys. This is probably a consequence of ordering, since it has been shown that mechanical properties are maximum for some intermediate value of the LRO parameter S [11]. A disordered alloy should thus first harden during ordering, then soften again; the present observations correspond to the first part of this process. 
In the boron-doped material only, some progressive hardening is observed before the temperature of long-range ordering. It might be caused by boron (which dissolves interstitially in $\mathrm{Ni}_{3} \mathrm{Al}$ [12]) diffusing to the dislocations and pinning them.

The increase in resistivity which takes place in stage A is not understood unambiguously at present. Two processes might be considered for interpreting it:

i. a short-range ordering of the disordered solid solution, which is known to increase resistivity in $\mathrm{Ni}(\mathrm{Al})$ alloys of lower concentration [13], or

ii. an increase of the specific resistivity of lattice defects, caused by the beginning of long-range ordering, an effect previously discussed by Rossiter [14] for the case of phonon resistivity.

At temperatures above the hardness and resistivity maxima (stage $B$ ), the main reasons for the simultaneous decrease of $\rho$ and $\mathrm{Hv}$ are probably the elimination of dislocations, the decrease of internal stresses and the growth of crystallite size, since the LRO parameter S does not change in this stage. Languillaume et al. [5] have shown that for $\mathrm{Ni}_{75} \mathrm{Al}_{25}$ after similar treatments, the level of internal stresses falls to zero after annealing at $833 \mathrm{~K}$. The shift of the recovery to higher temperatures in the boron-doped material may be assigned to a retarding effect of boron on the dislocation rerrangements and on the grainboundary migration ; another effect might possibly contribute to the temperature shift, : a reduced driving force in the boron-doped alloy as suggested by the smaller amplitude of the resistivity recovery in this stage.

The further grain growth in stage $\mathrm{C}$ has an important effect on the mechanical properties but does not cause much change in the resistivity values in the two materials. The slight resistivity increase observed between $833 \mathrm{~K}$ abd $1173 \mathrm{~K}$ results from a weak thermal disordering, as was shown in a previous investigation [9].

\section{CONCLUSIONS}

1. Shear plastic deformation under quasi-hydrostatic pressure allowed both pure and boron-doped $\mathrm{Ni}_{3} \mathrm{Al}$ to be highly cold worked, and resulted in completely disordered materials with a nanocrystalline structure.

2. The values of residual resistivity in both compounds are high, higher in pure Ni3Al is than in the Bdoped material.

3. The boron-doped material has enhanced thermal stability i.e. the recovery of microhardness and of resistivity, as well as long-range ordering, take place at temperatures higher than in pure Ni3Al.

Acknowledgement - The financial support of the Ministère de l'Enseignement Supérieur et de la Recherche of France is gratefully acknowledged by one of us (A.K.).

\section{References}

[1] Aoki K. and Izumi O., J. Jap. Inst. Metals 43 (1979) 1190.

[2] Baker I., Viens D.V. and Schulson E.M., J. Mat. Sci. 19 (1984) 1799.

[3] Zhou B., Chou Y.T. and Liu C.T., Intermetallics 1 (1993) 217-25.

[4] Smirnova N.A., Levit V.I., Pilyugin V.P., Kuznetzov R.I., Davydova L.A. and Sazoniova R.A., Phys. Met. and Metall., 61 (1986) 1170.

[5] Languillaume J., Chmelik F., Kapelski G., Bordeaux F., Nazarov A.A., Canova G., Valiev R.Z. and Baudelet B., Acta Metall Mater.41 (1993) 2953-2962.

[6] Liu C. T., White C.L. and Horton J. A., Acta metall. 33 (1985) 213

[7] Cullity B. D., Elements of X-ray Diffraction. (Addison-Wesley, Reading, Mass, 1969) pp. 383-395.

[8] Viltange M. and Dimitrov O., J. de Physique IV, Colloque C7, Supplement au J. de Physique III, 3 (1993) 977-980.

[9] Dimitrov C., Tarfa T. and Dimitrov O., Ordering and Disordering in Alloys, Ed. R.A. Yavari (Elsevier Applied Science, London,1992) 130-137.

[10] Valiev R.Z., Proceedings of the Conference Nano-94 (Stuttgart, October 3-7, 1994), in press

[11] Cahn R.W., Intermetallic Compounds, Ed. O. Izumi (The Japan Institute of Metals, Sendai, 1991) 771-778.

[12] Masahashi N., Takasugi T. and Izumi O., Acta metall. 36 (1988) 1815.

[13] Sitaud B. and Dimitrov O., Def. Diff. Forum 66-69 (1989) 477-482.

[14] Rossiter P., J. Phys. F 10 (1980) 419-465. 